Research Paper

International Journal of Medical Sciences

ISSN 1449-1907 www.medsci.org 2008 5(1):29-35

(C) Ivyspring International Publisher. All rights reserved

\title{
Association Study of Aromatase Gene (CYP19A1) in Essential Hypertension
}

\section{Masanori Shimodaira1, Tomohiro Nakayama², Naoyuki Sato ${ }^{3}$, Kosuke Saito 2,4, Akihiko Morita ${ }^{5}$, Ichiro Sato 6 , Teruyuki Takahashi', Masayoshi Soma ${ }^{8}$, Yoichi Izumi ${ }^{8}$}

1. MD Program, Nihon University School of Medicine, Tokyo, Japan

2. Division of Receptor Biology, Advanced Medical Research Center, Tokyo, Japan

3. Division of Genomic Epidemiology and Clinical Trials, Advanced Medical Research Center, Tokyo, Japan

4. Department of Applied Chemistry, Toyo University School of Engineering, Tokyo, Japan

5. Department of Neurology, Division of Neurology, Department of Medicine, Nihon University School of Medicine, Tokyo, Japan

6. Department of Obstetrics and Gynecology, Nihon University School of Medicine, Tokyo, Japan

7. Department of Neurology, Graduate School of Medicine, Nihon University, Tokyo, Japan

8. Division of Nephrology and Endocrinology, Department of Medicine, Nihon University School of Medicine, Tokyo, Japan

Correspondence to: Tomohiro Nakayama, MD, Division of Receptor Biology, Advanced Medical Research Center, Nihon University School of Medicine, Ooyaguchi-kamimachi, 30-1 Itabashi-ku, Tokyo 173-8610, Japan. Tel: +81 3-3972-8111 (ext.8205); Fax: +81 3-5375-8076; E-mail: tnakayam@med.nihon-u.ac.jp

Received: 2007.10.21; Accepted: 2008.02.05; Published: 2008.02.07

Background: As aromatase-deficient mice, which are deficient in estrogens, reportedly have reduced blood pressure, the aromatase gene (CYP19A1) is thought to be a susceptibility gene for essential hypertension (EH). The aim of the present study was to investigate the relationship between CYP19A1 and EH by examining single nucleotide polymorphisms (SNPs).

Methods: Five SNPs in the human CYP19A1 gene (rs1870049, rs936306, rs700518, rs10046 and rs4646) were selected, and an association study was performed in 218 Japanese EH patients and 225 age-matched normotensive (NT) individuals.

Results: There were significant differences between these groups in the distribution of genotypes rs700518 and rs10046 in male subjects, and genotypes rs700518, rs10046 and rs4646 in female subjects. On multiple logistic regression analysis, a significant association between rs700518 $(p=0.023)$ and $r s 10046(p=0.036)$ in male subjects and rs700518 in female subjects $(p=0.018)$ was noted. Interestingly, the risk genotypes of rs700518 and rs10046 showed a sex-dependent inverse relationship. Both SBP and DBP levels were higher in total (cases and controls) male subjects with the G/G genotype with rs700518 or the T/T genotype with rs10046 than in male subjects without the G/G genotype or T/T genotype. SBP levels were lower in female subjects with the G/G genotype with rs700518 than in female subjects without G/G. The A-T haplotype constructed with rs1870049 and rs10046 was a susceptibility marker for EH.

Conclusions: We confirmed that rs700518 and rs10046, as well as a haplotype constructed with rs1870049 and rs10046, in the human CYP19A1 gene can be used as genetic markers for gender-specific EH.

Key words: Essential hypertension, aromatase, CYP19A1, single nucleotide polymorphism, genetic

\section{Introduction}

High blood pressure or hypertension affects about $25 \%$ of adults and is an important risk factor for death from stroke, myocardial infarction and congestive heart failure. The main cause of hypertension is a primary condition known as essential hypertension (EH). $\mathrm{EH}$ is thought to be a multifactorial disease [1]. Several reports have indicated that there are susceptibility genes for $\mathrm{EH}$, including those for estrogen, estrogen receptor [2] and aromatase [3]. The final stage of estrogen synthesis is catalyzed by aromatase.

There are numerous proposed mechanisms by which estrogen may bring about beneficial effects on the cardiovascular system. However, the precise role of estrogens has been difficult to establish, perhaps due to their wide variety of actions. In humans, estrogen facilitates vasodilation by stimulating prostacyclin and nitric oxide synthesis, as well as decreasing the production of vasoconstrictor substances, such as cyclooxgenase-derived products, reactive oxygen species, angiotensin II and endothelin-1 [4]. Estrogen also reduces the number of angiotensin type I (AT1) receptors [5]. Furthermore, men are at higher risk of developing cardiovascular disease than premenopausal women, and age-matched women have been shown to have lower blood pressure than men [6].

The aromatase enzyme complex catalyzes the 
conversion of androgens to estrogens in a variety of tissues, including the ovary and placenta $[7,8]$, brain [9] and adipose tissue [10]. It was recently demonstrated that both estrogens and aromatase are produced in vascular tissue, particularly in smooth muscle cells [11] and endothelial cells [12]. It has been reported that aromatase-deficient (ArKO) mice, which are deficient in estrogens due to deletion of the aromatase gene, exhibit reduced blood pressure (BP)[3]. Thus, we hypothesized that aromatase is one of the factors affecting $\mathrm{BP}$, and that the aromatase gene is a susceptibility gene for hypertension, as single nucleotide polymorphisms (SNPs) in this gene are associated with differences in estrogen levels in human [13].

The human CYP19A1 gene, which encodes aromatase, consists of 503 amino acids and is located on chromosome 15q21.1 [14]. The gene is very unique; it contains 11 exons, with 9 exons being translated, interrupted by 10 introns (about $80 \mathrm{~kb}$, exon 2a to exon 2), and consists of approximately 130 kilobase pairs $(\mathrm{kb})$.

The aim of the present study was to investigate the relationship between the human CYP19A1 gene and $\mathrm{EH}$ by examining 5 SNPs in the human CYP19A1 gene (Figure 1) in Japanese individuals.
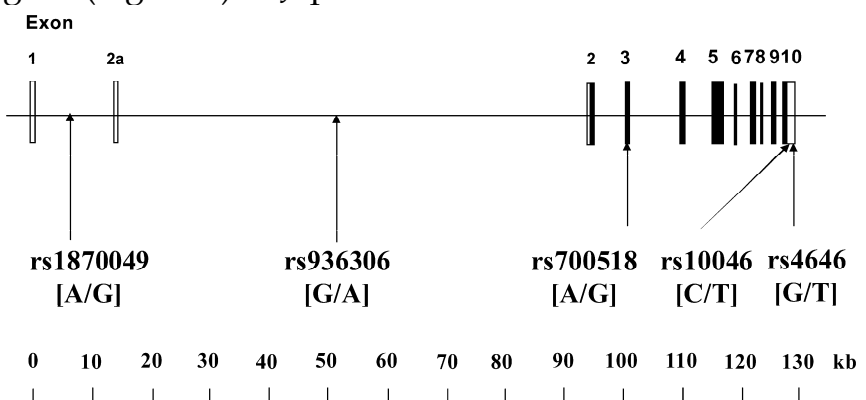

Figure 1. Organization of the human CYP19A1 gene and location of SNPs. The gene is approximately 130 kilobase pairs $(\mathrm{kb})$ in length, and has a total of 11 exons. Boxes indicate exons, and lines indicate introns and intergenic regions. Filled boxes indicate coding regions. There are two transcript variants; variant 1 does not include exon $2 \mathrm{a}$, and thus has a shorter 5 '-UTR than transcript variant 2; variant 2 includes exon $2 \mathrm{a}$. Both variants encode the same protein. Polymorphisms were expressed as nucleotide number on the sense strand of the CYP19A1 gene.

\section{Subjects and Methods}

\section{Subjects}

EH subjects were 218 patients diagnosed with $\mathrm{EH}$ according to the following criteria: seated systolic blood pressure (SBP) above $160 \mathrm{mmHg}$ and/or diastolic blood pressure (DBP) above $100 \mathrm{mmHg}$, on 3 occasions within 2 months after the first medical examination. None of the $\mathrm{EH}$ subjects were using anti-hypertensive medication. Patients diagnosed with secondary hypertension were excluded. Control subjects were 225 healthy, normotensive (NT) individuals. None of the controls had a family history of hypertension, and they all had SBP and DBP below 130 and $85 \mathrm{mmHg}$, respectively. A family history of hypertension was defined as prior diagnosis of hypertension in grandparents, uncles, aunts, parents or siblings. Both groups were recruited from the northern area of Tokyo, Japan, and informed consent was obtained from each individual according to a protocol approved by the Human Studies Committee of Nihon University [15].

\section{Biochemical analysis}

Plasma concentration of total cholesterol, and serum concentrations of creatinine and uric acid were measured using the methods of the Clinical Laboratory Department of Nihon University Hospital [16].

\section{Genotyping}

Using information regarding allelic frequencies of SNPs registered with the National Center for Biotechnology Information (NCBI) and Celera Discovery System-Applied Biosystems, 5 SNPs with minor allele frequencies greater than 20\% were selected. SNPs with relatively high minor allele frequencies have been shown to be useful as genetic markers for genetic association studies.

We selected 5 SNPs in the human CYP19A1 gene as markers for the genetic association experiment (Fig. 1). All 5 SNPs were confirmed using the NCBI website (accession numbers rs1870049, rs936306, rs700518, rs10046 and rs4646). rs1870049 and rs936306 are located in introns, rs700518 is a synonymous SNP that does not result in a change in amino acids, and rs10046 and rs4646 are located in the 3'-untranslated region. Genotypes were determined using Assays-on-Demand kits (Applied Biosystems, Branchburg, NJ) together with TaqMan ${ }^{\circledR}$ PCR. When allele-specific fluorogenic probes hybridize to the template during polymerase chain reaction (PCR), the 5'-nuclease activity of Taq polymerase is able to discriminate between alleles [17].

\section{Linkage disequilibrium (LD) analysis and haplotype-based case-control analysis}

LD analysis and haplotype-based case-control analysis were performed with SNPAlyze version 3.2.3 (Dynacom Co., Ltd., Yokohama, Japan) using 5 SNPs. The software is available from the following website: http://www.dynacom.co.jp/products/package/snpa lyze/index.html. We used $\left|\mathrm{D}^{\prime}\right|$ values of $>0.5$ to assign SNP locations to 1 haplotype block. SNPs with an $r^{2}$ value of $<0.5$ were selected as tagged. In the 
haplotype-based case-control analysis, the frequency distribution of the haplotypes was calculated by performing a chi-squared test using the contingency table method.

\section{Statistical analysis}

Data are shown as means $\pm S D$. Hardy-Weinberg equilibrium was assessed by chi-squared analysis in NT controls. The overall distribution of alleles was analyzed using $2 \times 2$ contingency tables, and the distribution of genotypes between $\mathrm{EH}$ patients and NT controls was tested using a 2-sided Fisher exact test and multiple logistic regression analysis, as the results of multiple logistic regression analyses after adjusting for confounding factors are known to be highly reliable. Statistical significance was established at $p<0.05$. Differences in clinical data between the EH and NT groups were assessed by student t-test. Statistical analyses were performed using SPSS software for Windows, version 12 (SPSS Inc., Chicago, IL, USA).

\section{Results}

Table 1 shows the clinical features of the EH patients and NT controls. SBP, DBP, body mass index (BMI) and pulse rate were significantly higher in the $\mathrm{EH}$ group than in the NT group. Age, serum concentrations of creatinine, and plasma concentrations of total cholesterol and uric acid did not significantly differ between the two groups.

Table 1. Characteristics of study participants.

\begin{tabular}{|c|c|c|c|c|c|c|c|c|c|c|c|c|}
\hline \multirow[b]{3}{*}{ Number of subjects } & \multicolumn{3}{|c|}{ Total } & & \multicolumn{4}{|c|}{ Men } & \multicolumn{4}{|c|}{ Women } \\
\hline & NT & $\mathrm{EH}$ & $\mathrm{p}$ Value & & NT & $\mathrm{EH}$ & $\mathrm{p}$ Value & & NT & $\mathrm{EH}$ & $\mathrm{p}$ Value & \\
\hline & 225 & 218 & & & 144 & 142 & & & 81 & 76 & & \\
\hline Age (years) & $50.3 \pm 9.01$ & $50.5 \pm 6.2$ & 0.812 & & $50.0 \pm 5.6$ & $50.2 \pm 6.7$ & 0.809 & & $50.9 \pm 13.1$ & $51.1 \pm 5.3$ & 0.899 & \\
\hline BMI $\left(\mathrm{kg} / \mathrm{m}^{2}\right)$ & $22.8 \pm 3.1$ & $24.8 \pm 3.8$ & $<0.001$ & $*$ & $23.0 \pm 2.9$ & $24.8 \pm 3.6$ & $<0.001$ & $*$ & $22.4 \pm 3.2$ & $24.8 \pm 4.1$ & $<0.001$ & * \\
\hline $\mathrm{SBP}(\mathrm{mmHg})$ & $111.8 \pm 11.0$ & $173.1 \pm 19.0$ & $<0.001$ & $*$ & $112.4 \pm 10.6$ & $171.2 \pm 16.9$ & $<0.001$ & $*$ & $110.9 \pm 11.6$ & $176.7 \pm 22.0$ & $<0.001$ & $*$ \\
\hline DBP (mmHg) & $68.8 \pm 8.6$ & $106.0 \pm 12.0$ & $<0.001$ & $*$ & $69.6 \pm 8.2$ & $106.8 \pm 10.9$ & $<0.001$ & $*$ & $67.4 \pm 9.2$ & $104.3 \pm 13.6$ & $<0.001$ & $*$ \\
\hline Pulse (beats/min) & $72.1 \pm 9.9$ & $77.5 \pm 15.6$ & $<0.001$ & * & $76.9 \pm 9.5$ & $77.8 \pm 16.0$ & $<0.001$ & $*$ & $74.3 \pm 10.2$ & $77.0 \pm 14.8$ & 0.257 & \\
\hline Creatinine $(\mathrm{mg} / \mathrm{dl})$ & $0.8 \pm 0.2$ & $0.8 \pm 0.2$ & 0.550 & & $0.9 \pm 0.2$ & $0.9 \pm 0.2$ & 0.505 & & $0.7 \pm 0.1$ & $0.7 \pm 0.2$ & 0.842 & \\
\hline Total cholesterol (mg/dl) & $203.3 \pm 41.1$ & $209.9 \pm 40.6$ & 0.103 & & $199.1 \pm 39.0$ & $204.2 \pm 39.9$ & 0.290 & & $210.8 \pm 44.0$ & $220.2 \pm 40.0$ & 0.177 & \\
\hline Uric acid (mg/dl) & $5.4 \pm 1.5$ & $5.6 \pm 1.5$ & 0.123 & & $6.0 \pm 1.3$ & $6.2 \pm 1.5$ & 0.093 & & $4.5 \pm 1.3$ & $4.6 \pm 1.0$ & 0.609 & \\
\hline Alcohol consumption $(\%)$ & 70.5 & 69.0 & 0.761 & & 77 & 85 & 0.084 & & 38.8 & 37.7 & 0.904 & \\
\hline Smoking (\%) & 40.7 & 51.9 & 0.038 & $*$ & 52.1 & 62.3 & 0.114 & & 21.6 & 31.9 & 0.117 & \\
\hline
\end{tabular}

BMI, body mass index; SBP, systolic blood pressure; DBP, diastolic blood pressure; HDL, high density lipoprotein;

NT, normotension; EH, essential hypertension. *Significant difference

Table 2 shows the distribution of genotypic and allelic frequencies of the 5 SNPs in each group. The genotype distribution of the each SNP in NT controls did not differ significantly from the Hardy-Weinberg equilibrium values (data not shown). The overall distributions of genotype and allele frequencies of all 5 SNPs did not significantly differ between the EH and total NT groups. However, some distributions showed significant gender-based differences between the groups. Among men, there were significant differences between the $\mathrm{EH}$ and NT groups in the distribution of rs700518 (P=0.012) and rs10046 genotypes $(P=0.005)$. In the dominant model, the $G / G$ genotype was significantly more frequent than the A/A\&A/G genotypes of rs700518 ( $\mathrm{P}=0.009)$, and the $\mathrm{T} / \mathrm{T}$ genotype was significantly more frequent than the $\mathrm{C} / \mathrm{C} \& \mathrm{C} / \mathrm{T}$ genotypes of $\operatorname{rs} 10046(\mathrm{P}=0.003)$ in $\mathrm{EH}$ men. Furthermore, the genotype distribution showed reciprocal findings in women when compared to men; in $\mathrm{EH}$ women, the G/G genotype was significantly less frequent than the $\mathrm{A} / \mathrm{A} \& \mathrm{~A} / \mathrm{G}$ genotypes of rs700518 $(\mathrm{P}=0.021)$, and the $\mathrm{T} / \mathrm{T}$ genotype was significantly less frequent than the $\mathrm{C} / \mathrm{C} \& \mathrm{C} / \mathrm{T}$ genotypes of rs10046 $(\mathrm{P}=0.030)$. The $\mathrm{T}$ allele of SNP rs4646 $(p=0.046)$ and the GT\&T/T genotype $(p=0.032)$ were significantly more frequent in $\mathrm{EH}$ women than in NT women.

Multiple logistic regression analysis revealed significant associations between rs700518 G/G and $\mathrm{EH}$ in men $(\mathrm{p}=0.023)$ and between $\mathrm{rs10046} \mathrm{T} / \mathrm{T}$ and $\mathrm{EH}$ in men $(p=0.036)$, even after adjustment for confounding factors such as age, BMI, creatinine, total cholesterol and uric acid. The calculated odds ratios were 2.48 (95\%CI: 1.11-5.53) and 2.10 (95\%CI: 1.04-4.23), respectively. Multiple logistic regression analysis revealed a significant association between rs700518 A/A\&A/G and EH in women ( $p=0.018)$, even after adjustment for confounding factors such as age, BMI, creatinine, total cholesterol and uric acid. The calculated odds ratio was 3.31 (95\%CI: 1.16-3.40). Multiple logistic regression analysis for rs10046 and rs4646 in women showed no significant associations (data not shown). The opposite direction of the association of rs700518 and rs10046 in men and women was confirmed by multiple logistic regression analysis ( $\mathrm{p}=0.001,<0.001$, respectively). 
Table 2. Genotype and allele distributions among NT subjects and patients with EH.

\begin{tabular}{|c|c|c|c|c|c|c|c|c|c|c|c|c|c|c|c|c|c|c|c|c|c|c|}
\hline & & & & Totals & subjects & & & & & & & Men & & & & & & & Jomen & & & \\
\hline & & & NT & & $\mathrm{EH}$ & $\begin{array}{c}\text { chi-square } \\
\text { p Value }\end{array}$ & Odss ratio & $95 \% \mathrm{Cl}$ & & NT & & $\mathrm{EH}$ & $\begin{array}{c}\text { chi-square } \\
\text { p Value }\end{array}$ & Odss ratio & $95 \% \mathrm{Cl}$ & & NT & & EH & $\begin{array}{c}\text { chi-square } \\
\text { p Value }\end{array}$ & Odss ratio & $95 \% \mathrm{Cl}$ \\
\hline Number of & paticipant & & 225 & & 218 & & & & & 144 & & 142 & & & & & 81 & & 76 & & & \\
\hline $\begin{array}{c}\text { Variants } \\
\text { rs } 1870049\end{array}$ & 9 Genotype & & & & & & & & & & & & & & & & & & & & & \\
\hline & $\mathrm{A} / \mathrm{A}$ & 144 & 40.640 & 134 & +0.615 & & & & 89 & 0.618 & 87 & 0.613 & & & & 55 & 0.679 & 47 & 0.618 & & & \\
\hline & $\mathrm{A} / \mathrm{G}$ & 72 & 0.320 & 75 & 0.344 & & & & 48 & 0.333 & 50 & 0.352 & & & & 24 & 0.296 & 25 & 0.329 & & & \\
\hline & $\mathrm{G} / \mathrm{G}$ & 9 & 0.040 & 9 & 0.041 & 0.856 & 1.11 & $0.76-1.64$ & 7 & 0.049 & 5 & 0.035 & 0.826 & 1.40 & $0.43-4.52$ & 2 & 0.025 & 4 & 0.053 & 0.561 & 2.19 & $0.39-12.3$ \\
\hline & Allele & & & & & & & & & & & & & & & & & & & & & \\
\hline & $\mathrm{A}$ & 360 & 0.800 & 343 & 0.787 & & & & 224 & 0.783 & 224 & 0.789 & & & & 134 & 40.827 & 119 & 0.783 & & & \\
\hline & $\mathrm{G}$ & 90 & 0.200 & 93 & 0.213 & 0.625 & 1.08 & $0.78-1.50$ & 62 & 0.217 & 60 & 0.211 & 0.907 & 1.03 & $0.69-1.54$ & 28 & 0.173 & 33 & 0.217 & 0.322 & 1.32 & $0.76-2.33$ \\
\hline rs936306 & Genotype & & & & & & & & & & & & & & & & & & & & & \\
\hline & $\mathrm{G} / \mathrm{G}$ & 88 & 0.391 & 89 & 0.408 & & & & 56 & 0.392 & 60 & 0.423 & & & & 31 & 0.383 & 29 & 0.382 & & & \\
\hline & $\mathrm{G} / \mathrm{A}$ & 102 & 20.453 & 104 & 0.477 & & & & 63 & 0.441 & 66 & 0.465 & & & & 39 & 0.481 & 38 & 0.500 & & & \\
\hline & $\mathrm{A} / \mathrm{A}$ & 35 & 0.156 & 25 & 0.115 & 0.454 & & & 24 & 0.168 & 16 & 0.113 & 0.420 & & & 11 & 0.136 & 9 & 0.118 & 0.942 & & \\
\hline & Allele & & & & & & & & & & & & & & & & & & & & & \\
\hline & G & 278 & 30.618 & 282 & 0.647 & & & & 177 & 0.615 & 186 & 0.655 & & & & 101 & 10.623 & 96 & 0.632 & & & \\
\hline & $\mathrm{A}$ & 172 & 20.382 & 154 & +0.353 & 0.371 & 1.13 & $0.86-1.49$ & 111 & 0.385 & 98 & 0.345 & 0.316 & 1.19 & $0.85-1.67$ & 61 & 0.377 & 56 & 0.368 & 0.882 & 1.04 & $0.66-1.64$ \\
\hline rs 700518 & Genotype & & & & & & & & & & & & & & & & & & & & & \\
\hline & $\mathrm{A} / \mathrm{A}$ & 82 & 0.364 & 88 & 0.404 & & & & 55 & 0.382 & 58 & 0.408 & & & & 27 & 0.333 & 30 & 0.395 & & & \\
\hline & $\mathrm{A} / \mathrm{G}$ & 111 & 10.493 & 95 & 0.436 & & & & 77 & 0.535 & 57 & 0.401 & & & & 34 & 0.420 & 38 & 0.500 & & & \\
\hline & $\mathrm{G} / \mathrm{G}$ & 32 & 0.142 & 35 & 0.161 & 0.478 & 1.18 & $0.80-1.73$ & 12 & 0.083 & 27 & 0.190 & 0.012 & * 2.58 & $1.25-5.33 * \#$ & 20 & 0.247 & 8 & 0.105 & 0.068 & 2.79 & $1.14-6.79 * \#$ \\
\hline & Allele & & & & & & & & & & & & & & & & & & & & & \\
\hline & A & 275 & 0.611 & 271 & 0.622 & & & & 187 & 0.649 & 173 & 0.609 & & & & 88 & 0.543 & 98 & 0.645 & & & \\
\hline & G & 175 & 0.389 & 165 & 0.378 & 0.749 & 1.05 & $0.80-1.37$ & 101 & 0.351 & 111 & 0.391 & 0.320 & 1.19 & $0.85-1.67$ & 74 & 0.457 & 54 & 0.355 & 0.067 & 1.53 & $0.97-2.40$ \\
\hline rs 10046 & Genotype & & & & & & & & & & & & & & & & & & & & & \\
\hline & $\mathrm{C} / \mathrm{C}$ & 66 & 0.293 & 66 & 0.303 & & & & 44 & 0.306 & 46 & 0.324 & & & & 22 & 0.272 & 20 & 0.263 & & & \\
\hline & $\mathrm{C} / \mathrm{T}$ & 116 & 60.516 & 103 & 0.472 & & & & 83 & 0.576 & 60 & 0.423 & & & & 33 & 0.407 & 43 & 0.566 & & & \\
\hline & $\mathrm{T} / \mathrm{T}$ & 43 & 0.191 & 49 & 0.225 & 0.591 & 1.23 & $0.77-1.94$ & 17 & 0.118 & 36 & 0.254 & 0.005 & * 2.54 & $1.35-4.77 * \#$ & 26 & 0.321 & 13 & 0.171 & 0.061 & 2.29 & $1.07-4.89 *$ \\
\hline & Allele & & & & & & & & & & & & & & & & & & & & & \\
\hline & C & 248 & 80.551 & 235 & 0.539 & & & & 171 & 0.594 & 152 & 0.535 & & & & 77 & 0.475 & 83 & 0.546 & & & \\
\hline & $\mathrm{T}$ & 202 & 20.449 & 201 & 0.461 & 0.717 & 1.05 & $0.81-1.37$ & 117 & 0.406 & 132 & 0.465 & 0.158 & 1.27 & $0.91-1.77$ & 85 & 0.525 & 69 & 0.454 & 0.210 & 1.32 & $0.85-2.07$ \\
\hline rs 4646 & Genotype & & & & & & & & & & & & & & & & & & & & & \\
\hline & $\mathrm{G} / \mathrm{G}$ & 119 & 0.529 & 114 & +0.523 & & & & 71 & 0.493 & 82 & 0.577 & & & & 48 & 0.593 & 32 & 0.421 & & & \\
\hline & $\mathrm{G} / \mathrm{T}$ & 85 & 0.378 & 83 & 0.381 & & & & 55 & 0.382 & 44 & 0.310 & & & & 30 & 0.370 & 39 & 0.513 & & & \\
\hline & $\mathrm{T} / \mathrm{T}$ & 21 & 0.093 & 21 & 0.096 & 0.990 & 1.02 & $0.71-1.49$ & 18 & 0.125 & 16 & 0.113 & 0.347 & 1.41 & $0.88-2.24$ & 3 & 0.037 & 5 & 0.066 & 0.094 & 2.00 & $1.06-3.78 *$ \\
\hline & Allele & & & & & & & & & & & & & & & & & & & & & \\
\hline & $\mathrm{G}$ & 323 & 30.718 & 311 & 0.713 & & & & 197 & 0.684 & 208 & 0.732 & & & & 126 & 60.778 & 103 & 0.678 & & & \\
\hline & $\mathrm{T}$ & 127 & 70.282 & 125 & 0.287 & 0.883 & 1.02 & $0.76-1.37$ & 91 & 0.316 & 76 & 0.268 & 0.203 & 1.26 & $0.88-1.81$ & 36 & 0.222 & 49 & 0.322 & 0.046 & * $\quad 1.67$ & $1.01-2.75 *$ \\
\hline
\end{tabular}

NT, normotension; EH, essential hypertension.

$95 \% \mathrm{CI}, 95 \%$ confidence interval

Odds ratios and $95 \% \mathrm{CIs}$ were calculated as the risks of the susceptibility allele or genotype(s) for EH.

* Significant differences by chi-square analysis

\#Significant differences by multiple logistic regression analysis

Clinical characteristics of the study participants by genotype are shown in Table 3. Genotypes showing significant differences in distribution on multiple logistic regression analysis were selected for analysis. Both SBP and DBP levels were higher in total (EH plus NT) male subjects with the G/G genotype in rs700518 than in male subjects without the G/G genotype. Furthermore, both SBP and DBP levels were higher in total male subjects with the T/T genotype in rs10046 than in male subjects without the $\mathrm{T} / \mathrm{T}$ genotype. In contrast, SBP levels were higher in total female subjects with the $\mathrm{A} / \mathrm{A} \& \mathrm{~A} / \mathrm{G}$ genotype in rs700518than in female subjects without the A/A\&A/G genotype.

LD patterns in the CYP19A1 gene are illustrated by their $\left|D^{\prime}\right|$ values in NT groups (Table 4). The $\left|D^{\prime}\right|$ values indicate that all $5 \mathrm{SNPs}$ are located in 1 haplotype block, as most $\left|\mathrm{D}^{\prime}\right|$ values were over 0.5, except for rs1870049-rs700518, rs1870049-rs10046 and rs936306-rs10046. All pair-wise SNPs, except rs700518-rs10046, were available for the performance of a haplotype-based case-control study because all $\mathrm{r}^{2}$ values were below 0.5 . Because $\mathrm{r}^{2}$ values calculated for the rs700518 and rs10046 SNPs were large, we did not perform a haplotype-based association study using the 2 SNPs in the same analysis. All 18 combinations of pair-wise SNPs were analyzed in men and women. Significant differences in overall distribution were only seen for the rs1870049 and rs10046 combination in men. Thus, the A-C haplotype is a resistance marker for $\mathrm{EH}$, while the A-T haplotype is a susceptibility marker for $\mathrm{EH}$. There is no overall distribution showing a significant difference in women (Table 5). 
Table 3. Clinical characteristics of the study partipants in each genotype.

\section{Men}

Number of subjects

Age (years)

BMI $\left(\mathrm{kg} / \mathrm{m}^{\llcorner}\right)$

$\mathrm{SBP}(\mathrm{mmHg})$

DBP (mmHg)

Puilse (beats/minin)

Creatinine (mg/dl)

Total cholesterol

Uric acid (mg/dl)

Alcohol consumption (

Smoking (\%)

\begin{tabular}{cccc}
\multicolumn{4}{c}{ rs700518 } \\
\hline $\mathrm{A} / \mathrm{A} \& \mathrm{~A} / \mathrm{G}$ & $\mathrm{G} / \mathrm{G}$ & $\mathrm{p}$ Value & \\
247 & 39 & & \\
$50.2 \pm 6.1$ & $49.7 \pm 6.1$ & 0.666 & \\
$23.9 \pm 3.5$ & $24.1 \pm 3.1$ & 0.820 & \\
$139.4 \pm 32.1$ & $155.6 \pm 33.1$ & 0.004 & $*$ \\
$86.7 \pm 20.8$ & $96.3 \pm 20.2$ & 0.008 & $*$ \\
$75.3 \pm 14.6$ & $73.1 \pm 11.0$ & 0.453 & \\
$0.9 \pm 0.2$ & $1.0 \pm 0.2$ & 0.193 & \\
$202.2 \pm 39.6$ & $197.9 \pm 38.3$ & 0.557 & \\
$6.1 \pm 1.4$ & $6.0 \pm 1.4$ & 0.795 & \\
82.8 & 76.7 & 0.415 & \\
59.3 & 44.1 & 0.819 &
\end{tabular}

\begin{tabular}{cccc}
\multicolumn{4}{c}{ rs10046 } \\
\hline $\mathrm{C} / \mathrm{C} \& \mathrm{C} / \mathrm{T}$ & $\mathrm{T} / \mathrm{T}$ & $\mathrm{p}$ Value & \\
233 & 53 & & \\
$50.1 \pm 6.2$ & $49.9 \pm 5.8$ & 0.812 & \\
$23.9 \pm 3.5$ & $24.2 \pm 3.1$ & 0.511 & \\
$138.7 \pm 32.1$ & $154.2 \pm 32.5$ & 0.002 & $*$ \\
$86.3 \pm 20.7$ & $95.5 \pm 20.8$ & 0.004 & $*$ \\
$75.3 \pm 15.0$ & $73.7 \pm 10.1$ & 0.522 & \\
$0.9 \pm 0.2$ & $0.9 \pm 0.2$ & 0.262 & \\
$201.0 \pm 39.7$ & $204.6 \pm 38.4$ & 0.555 & \\
$6.1 \pm 1.4$ & $6.0 \pm 1.3$ & 0.835 & \\
82.2 & 81.0 & 0.848 & \\
60.0 & 51.1 & 0.383 &
\end{tabular}

Table 4. Pairwise LD in CYP19A1 gene of each NT group.

\begin{tabular}{cccccc}
\hline SNP & rs1870049 & rs936306 & rs700518 & rs10046 & rs4646 \\
\hline rs1870049 & & 0.934 & 0.176 & 0.257 & 0.653 \\
rs936306 & 0.352 & & 0.567 & 0.384 & 0.764 \\
rs700518 & 0.005 & 0.127 & & 0.967 & 1.000 \\
rs10046 & 0.013 & 0.074 & 0.730 & & 0.976 \\
rs4646 & 0.042 & 0.142 & 0.250 & 0.305 & \\
\hline
\end{tabular}

LD, linkage disequilibrium; SNP, single-nucleotide polymorphism.

Upper right triangle shows absolute $\mathrm{D}^{\prime}$ values. $\mathrm{D}^{\prime}>0.5$ are shown as shaded values.

Lower left triangle shows $r^{2}$ values. $r^{2}>0.5$ are shown as shaded values.

Table 5. Haplotypes showing significant differences in overall distribution between NT controls and EH patients in men.

\begin{tabular}{|c|c|c|c|c|c|c|c|c|}
\hline \multirow{3}{*}{ Combination of SNPS } & \multicolumn{2}{|c|}{ Overall distribution } & \multicolumn{6}{|c|}{ Distribution of Individual haplotypes } \\
\hline & Chi-square & $\mathrm{p}$ value & Haplotype & NT & EH & Chi-square & p-value & \\
\hline & & & & 288 & 284 & & & \\
\hline \multirow{4}{*}{ rs1870049-rs10046 } & \multirow{4}{*}{8.1} & \multirow{4}{*}{0.044} & $\mathrm{~A}-\mathrm{C}$ & 0.464 & 0.381 & 4.232 & 0.040 & $*$ \\
\hline & & & A-T & 0.320 & 0.408 & 4.895 & 0.027 & * \\
\hline & & & G-C & 0.129 & 0.155 & 0.823 & 0.364 & \\
\hline & & & $\mathrm{G}-\mathrm{T}$ & 0.086 & 0.057 & 1.995 & 0.158 & \\
\hline
\end{tabular}

* significant difference

\section{Discussion}

Human aromatase deficiency was first reported in 1995. The disorder is very rare, and only a few cases have been reported [18-20]. Male patients with aromatase deficiency exhibit eunuchoid skeletal proportions, macroorchidism, sexually precocity. In contrast, female patients with the disease develop progressive signs of virilization, pubertal failure with no signs of estrogen action, hypergonadotropic hypogonadism, polycystic ovaries on pelvic sonography, and tall stature. Common clinical data in men and women with aromatase deficiency are high levels of plasma testosterone, androsterone, FSH and
LH, and low estradiol and estrone $[18,19]$. They also have homozygous or compound heterozygous mutations in the CYP19A1 gene. Interestingly, male patients with aromatase deficiency exhibit hypertension $[19,20]$.

In the present study, the findings regarding genotype and allele distributions were particularly interesting from the viewpoint of gender differences. The gender differences in genotype and allele distributions were similar between rs700518 and rs10046, while the overall distribution of genotypes was significantly different between the EH and the NT groups. Blood pressure values for each genotype were 
similar between rs700518 and rs10046. These results were consistent with those of LD analysis showing that rs700518 and rs10046 were closely linked with a large $r^{2}$.

Although systolic BP in ArKO female mice was similar to that in age- and weight-matched wild-type (WT) mice, diastolic and mean BP were lower in ArKO mice $(-6.3 \pm 1.9$ and $-4.6 \pm 2.1 \mathrm{mmHg}$, respectively). The baroreflex sensitivity of ArKO mice was $46 \%$ that observed in WT mice [3]. However, there have been no previous studies on male ArKO mice or comparing data between male and female ArKO mice.

Some investigators have been reported the CYP19A1 gene variants associated with hypertension. Peter et al. found suggestive evidence of gender-specific contributions of rs4646 to DBP variation in women in the Framingham Heart Study [21]. $\mathrm{DBP}$ in patients with $\mathrm{T} / \mathrm{T}$ genotype was significantly higher than in those without this genotype. This is very interesting because the frequencies of $\mathrm{EH}$ women with $\mathrm{T} / \mathrm{T}$ genotype or $\mathrm{T}$ alleles were significantly higher in the present study when compared to NT women. In addition, our data for rs4646 also showed no significant results in men, which is also in agreement the report by Peter et al. Recently, Ramirez-Lorca et al. reported that DBP in subjects with C/C genotype in rs10046 was significantly higher than in those without $\mathrm{C} / \mathrm{C}$ genotype [22]. This corresponds with our data, as the frequency of $\mathrm{EH}$ patients with the $\mathrm{T} / \mathrm{T}$ genotype was significantly lower than that of NT subjects. However, the opposite direction of the association in men found in our study was not detected in men in their study. There are several reasons for this discrepancy between the results in our study and those of previous studies. Our study used a case-control design with patients clearly diagnosed by EH criteria, while Ramirez-Lorca et al. used a population-based cohort in the general population. Therefore, the data on blood pressure in each genotype from their study were within normal ranges. This discrepancy may be attributed to both the different criteria used in subject selection, and to racial differences in the populations studied.

In the present study, none of the SNPs were thought to have functional consequences. Possible functional mutations in the CYP19A1 gene with quantitative effects on genomic transcription, posttranslational processing or amino acid sequence have a strong linkage with genetic markers such as rs10046, and subsequently reduce the activity of aromatase associated with $\mathrm{EH}$. Unfortunately, we were not able to obtain samples to measure plasma sex hormones levels and aromatase activity, due to the difficulty in obtaining written informed consent for blood examinations from subjects not receiving medications.

In conclusion, the present study was the first to examine correlations between the human CYP19A1 gene (encoding aromatase) and $\mathrm{EH}$. The present data indicate that the CYP19A1 gene is a gender-specific candidate genetic marker for $\mathrm{EH}$.

\section{Acknowledgments}

We would like to thank Ms. K. Sugama for technical assistance. This work was supported by a grant from the Ministry of Education, Culture, Sports, Science and Technology of Japan (High-Tech Research Center, Nihon University), and a research grant from the alumni association of Nihon University School of Medicine and TORAY, Japan.

\section{Conflict of interest}

The authors have declared that no conflict of interest exists.

\section{References}

1. Dominiczak AF, Negrin DC, Clark JS, Brosnan MJ, McBride MW, Alexander MY. Genes and hypertension: from gene mapping in experimental models to vascular gene transfer strategies. Hypertension. 2000; 35: 164-72.

2. Zhu Y, Bian Z, Lu P, Karas RH, Bao L, Cox D, Hodgin J, Shaul PW, Thoren P, Smithies O, Gustafsson JA, Mendelsohn ME. Abnormal vascular function and hypertension in mice deficient in estrogen receptor $\beta$. Science. 2002; 295: 505-8.

3. Head GA, Obeyesekere VR, Jones ME, Simpson ER, Krozowski ZS. Aromatase-deficient (ArKO) mice have reduced blood pressure and baroreflex sensitivity. Endocrinology. 2004; 145: 4286-91.

4. Tostes RC, Nigro D, Fortes ZB, Carvalho MH. Effects of estrogen on the vascular system. Braz J Med Biol Res. 2003; 36: 1143-58.

5. Wu Z, Zheng W, Sandberg K. Estrogen regulates adrenal angiotensin type 1 receptors by modulating adrenal angiotensin levels. Endocrinology. 2003; 144: 1350-6.

6. Reckelhoff JF. Gender differences in the regulation of blood pressure. Hypertension. 2001; 37: 1199-208.

7. McNatty KP, Makris A, DeGrazia C, Osathanondh R, Ryan KJ. The production of progesterone, androgens, and estrogens by granulosa cells, thecal tissue, and stromal tissue from human ovaries in vitro. J Clin Endocrinol Metab. 1979; 49: 687-99.

8. Ryan KJ. Biological aromatization of steroids. J Biol Chem. 1959; 234: 268-72.

9. Ryan KJ, Naftolin F, Reddy V, Flores F, Petro Z. Estrogen formation in the brain. Am J Obstet Gynecol. 1972; 114: 454-60.

10. Schindler AE, Ebert A, Friedrich E. Conversion of androstenedione to estrone by human tissue. J Clin Endocrinol Metab. 1972; 35: 627-30.

11. Harada N, Sasano H, Murakami H, Ohkuma T, Nagura H, Takagi Y. Localized expression of aromatase in human vascular tissues. Circ Res. 1999; 84: 1285-91.

12. Sasano H, Murakami H, Shizawa S, Satomi S, Nagura H, Harada N. Related Articles, Links Aromatase and sex steroid receptors in human vena cava. Endocr J. 1999; 46: 233-42.

13. Dunning AM, Dowsett M, Healey CS, Tee L, Luben RN, Folkerd E, Novik KL, Kelemen L, Ogata S, Pharoah PD, Easton DF, Day NE, Ponder BA. Polymorphisms associated with circulating sex 
hormone levels in postmenopausal women. J Natl Cancer Inst. 2004; 96: 936-45.

14. Chen SA, Besman MJ, Sparkes RS, Zollman S, Klisak I, Mohandas T, Hall PF, Shively JE. Human aromatase: cDNA cloning, Southern blot analysis, and assignment of the gene to chromosome 15. DNA. 1988; 7: 27-38.

15. Kosuge K, Soma M, Nakayama T, Aoi N, Sato M, Izumi $Y$, Matsumoto K. A Novel Variable Number of Tandem Repeat of the Natriuretic Peptide Precursor B gene's 5'-Flanking Region is Associated with Essential Hypertension among Japanese Females. Int J Med Sci. 2007; 4: 146-52.

16. Nakayama T, Soma M, Haketa A, Aoi N, Kosuge K, Sato M, Kanmatsuse K, Kokubun S. Haplotype analysis of the prostacyclin synthase gene and essential hypertension. Hypertens Res. 2003; 26: 553-7.

17. Morita A, Nakayama T, Soma M, Mizutani T. The association between the calcitonin-related peptide a (CALCA) gene and essential hypertension in Japanese subjects. Am J Hypertens. 2007; 20: 527-32.

18. Mullis PE, Yoshimura N, Kuhlmann B, Lippuner K, Jaeger P, Harada H. Aromatase deficiency in a female who is compound heterozygote for two new point mutations in the P450arom gene: impact of estrogens on hypergonadotropic hypogonadism, multicystic ovaries, and bone densitometry in childhood.J Clin Endocrinol Metab. 1997; 82: 1739-45.

19. Morishima A, Grumbach MM, Simpson ER, Fisher C, Qin K. Aromatase deficiency in male and female siblings caused by a novel mutation and the physiological role of estrogens. J Clin Endocrinol Metab. 1995; 80: 3689-98.

20. Mendelsohn ME. Protective effects of estrogen on the cardiovascular system. Am J Cardiol. 2002; 89(Suppl 12): 12E-17E.

21. Peter I, Shearman AM, Zucker DR, Schmid CH, Demissie S, Cupples LA, Larson MG, Vasan RS, D'Agostino RB, Karas RH, Mendelsohn ME, Housman DE, Levy D. Variation in estrogen-related genes and cross-sectional and longitudinal blood pressure in the Framingham Heart Study. J Hypertens. 2005; 23: 2193-200.

22. Ramirez-Lorca R, Grilo A, Martinez-Larrad MT, Manzano L, Serrano-Hernando FJ, Moron FJ, Perez-Gonzalez V, Gonzalez-Sanchez JL, Fresneda J, Fernandez-Parrilla R, Moñux G, Molero E, Sanchez E, Martinez-Calatrava MJ, Saban-Ruiz J, Ruiz A, Saez ME, Serrano-Rios M. Sex and body mass index specific regulation of blood pressure by CYP19A1 gene variants. Hypertension. 2007; 50: 884-90. 